\section{THE CHARRED PLANT REMAINS}

Mhairi Hastie \& Scott Timpany

The charred plant assemblages from the 1999 and 2008 excavations at Doune are presented here. Samples were taken in both excavations from the main features across the site(s), including identifiable buildings and associated pits, together with bread ovens and the base of a possible furnace. Charred cereal grains were present in most contexts from across the site, with particularly rich assemblages attained from contexts associated with Buildings 3 and 5.

\subsection{Method}

\subsubsection{Plant macrofossil assessment and charcoal identifications}

Samples were processed in laboratory conditions using a standard floatation method (cf Kenward et al 1980). Identifications were confirmed using modern reference material and seed atlases, including Cappers et al (2006). Plant taxonomic nomenclature used in Tables 6 and 7 follows the order of Stace (1997). Charcoal identifications were made using wood keys by Schweingruber (1990) and IAWA (1989).

\subsection{Results}

The results for the two phases of excavation are presented in Tables $6 \& 7$ (in Appendix 5: Composition of plant remains from Doune Primary School) and Table 8 (in Appendix 6: Composition of the charcoal from Doune Primary School), which show the materials recovered from both the retent and flot samples and take into account the suggestions of van der Veen et al (2007). All plant material was preserved through charring.

\subsubsection{Charred cereals}

Charred cereal grains dominate the charred plant assemblage from both phases of excavation (see Tables 6 \& 7). Grains of hulled barley (Hordeum vulgare), including rare quantities of naked barley (Hordeum vulgare var nudum) were recovered, together with oat (Avena sp), club/bread wheat (Triticum aestivo-compactum), emmer wheat (Triticum dicoccum) and spelt wheat (Triticum spelta).
Where possible the hulled barley has been recorded as either having a 'straight' or 'twisted' central groove to potentially differentiate the presence of two-row (straight) and six-row (twisted) barley. A number of degraded cereal grains were also present, which could not be identified to species or family level; these are recorded as indeterminate cereal grains (Cereal indet). Together with the cereal grain, rare quantities of barley and possible spelt wheat rachis fragments were recovered from two samples (see Tables $6 \& 7$ ).

\subsubsection{Wild taxa}

A wide variety of wild taxa are present within the assemblage, with generally increased numbers in those contexts containing large numbers of cereal grains. In general the wild taxa fall into two categories; those relating to agricultural weeds and those relating to damp/boggy ground. Agricultural weeds are present in samples from both phases of excavations and include taxa such as ribwort plantain (Plantago lanceolata), corn spurry (Spergula arvensis), sheep's sorrel (Rumex acetosella agg), buttercups (Ranunculus sp) and corn marigold (Chrysanthemum segetum). A number of taxa relating to damp/boggy ground are present in the assemblage, including a suite of sedge species (Carex sp), wood-rushes (Luzula sp), violets (Viola sp) and spike-rushes (Eleocharis sp). Grasses (Poaceae sp) are also well represented in the assemblage, with meadow grass (Poa sp), brome/false brome (Bromus/Brachypodium $\mathrm{sp}$ ) and heath grass (Sieglingia decumbens sp) present, together with a number of grains, which could not be identified to species level and are listed as indeterminate. The only arboreal taxon present is hazel (Corylus avellana), through charred nutshell recovered from two contexts (see Table 8).

\subsubsection{Charcoal}

A small number of arboreal species were identified during the charcoal analysis. The assemblage is largely dominated by oak (Quercus sp) and hazel charcoal. Present in lesser quantities are: alder (Alnus glutinosa), birch (Betula sp), willow (Salix sp) and plum/rowan (Rosaceae indet). The results are shown in Table 8. 


\subsubsection{Discussion}

\subsubsection{The intervallum: bread ovens and furnace}

Samples were taken from contexts relating to each of the five bread ovens present on the site (DPS99 C002, 006, 012, 018 and 023), together with the associated rake-out deposits (C008 and 029) surrounding the ovens. The assemblages recovered from the ovens are generally poor, with all but two contexts (C012 and 023) being sterile. C023 contained only a single charred indeterminate cereal grain. The greatest concentration of cereal grain was recovered from $\mathrm{C} 012$ (relating to oven C024), which contained in excess of 70 grains of hulled barley, together with a significant number of wheat grains, some of which have been identified as spelt wheat. Wild taxa are also present in this assemblage. A similar grain assemblage is also shown in one of the rake-out deposits (C008) although in smaller quantities (see Table 7).

The charred cereal grains present in bread oven C024 are likely to reflect the last use of the oven: with bread ovens being cleaned out on a regular basis there would be less build-up of grains and associated wild taxa accumulating within them (Clapham 2007). As the primary use of the bread ovens would have been for baking rather than cooking, the cereals present within bread oven $\mathrm{C} 024$ are likely to have derived from secondary sources, such as adhering to the sides of bread (Clapham 2007) or accidental transfer from people. However, roasting of grain in the ovens to prevent spoilage cannot be ruled out entirely (eg Robertson 1941-2) and this may well explain the presence of arable weeds within the assemblage.

It is likely that both barley and wheat were being used in bread production at Doune, as is reflected in the overall grain assemblage recovered from the site. Barley bread is thought to have been inferior to wheat bread but was used by the Roman military, particularly to feed lower ranked soldiers, while higher ranking soldiers would have consumed the wheat bread (Davies 1971). The higher proportion of barley at Doune could suggest bread was largely being produced for the lower ranked soldiers or it could simply reflect local availability of cereal types. It is thought cereals would have been requisitioned from the local population by the Roman army (Johnson 1983). Barley is known to have been the more common cereal produced in the north of Britain (Dickson 1989) and has been evidenced from other Roman sites in Scotland dating to around the time of the occupation of the fort at Doune such as Bearsden (Knights et al 1983), Cramond (Hastie 2006) and Elginhaugh (Clapham 2007). Wheat such as spelt wheat is inferred to have been grown in Scotland during this period from its presence at Iron Age sites such as Culduthel, near Inverness (Timpany 2007). However, it is likely it was grown in smaller quantities than barley and thus the spelt wheat at Doune may reflect a combination of wheat brought to the site by the Roman army together with local production (Dickson 1989; Boardman \& Dickson 1995; Dickson \& Dickson 2000). Together with the baking of bread it is suggested that cereals would also have been used to make foodstuffs such as porridge and soups (Dickson 1989).

Charcoal fragments recovered from the bread ovens and the rake-out show an oak and hazel dominated assemblage (see Table 8), with smaller quantities of willow, alder and plum/rowan, indicating the use of local wood for fuel. The high number of sedge nutlets within the assemblage from bread oven C024 (C012) suggest that turf/peat may also have been used on occasion to fuel the ovens.

One sample was taken from the base of the possible furnace (DPS99 C003), which is thought to have been used primarily for metalworking and the manufacture of iron products on site (see below). However, the presence of over 100 cereal grains dominated by barley, together with occasional wild taxa of arable weeds such as buttercups, knotgrass and chickweed (Stellaria sp of $S$ media) from this context (see Table 7) would seem out of place for a furnace assemblage. Given the close proximity of this context to that of the oven rake-out deposits (C008), it seems more likely that this context contains a mix of both oven and furnace waste. Thus the shallow pit feature containing C003 may represent an accumulation of rake-out material from both the ovens and furnace. The charcoal assemblage from this context is dominated by oak fragments with rare quantities of hazel, plum/rowan and possible alder (see Table 8 ), all of which were likely to come from local sources. The dominance of oak charcoal, which burns at high temperatures, reflects the industrial nature of this area of the site for both metalworking and baking. 


\subsubsection{Buildings and pits in the interior of the fort}

Five samples have been analysed from Building 1 . These were taken from one of the construction trenches (DPS99 C053), Pit C005 (C004 and 005), the top fill of Pit C011 (C010), and Pit C055 (C056). Samples were also analysed from the fill of the construction trenches of Building 2 (C042) and Building 3 (C094), and Pit 105 (C106).

The samples associated with Building 1, the most substantial structure excavated, show a general spread of grain across the interior of the structure, with grain becoming trapped in the fills of demolition pits and beam slots, following the destruction of the structure. The grain assemblage for the structure is dominated by barley, with lesser incidences of spelt wheat and oat (see Table 6). The wild taxa present are all indicative of arable weeds. Identification of charcoal fragments from this structure show utilisation of oak and hazel together with wood of alder, willow and plum/rowan (see Table 8 ). The absence of any charcoal fragments of substantial size suggests they are more likely to represent the remnants of fuel wood rather than building timbers, although it is likely that oak and hazel would have also have been the main arboreal taxa used to provide construction materials for the buildings.

The arboreal taxa represented are suggestive of utilisation of mixed dryland/wetland woodland, with species such as oak, hazel and plum/rowan preferring drier areas, and alder and willow indicative of damp/wet areas. It is generally observed that by the Roman period large-scale clearance of woodland had already taken place to make way for agricultural land (eg Tipping 1997; Clapham 2007). However, the location of the fort near to the River Teith suggests that all of these species may have been growing locally on the wetland around the river and the immediate dryland. The presence of oak woodland in this area during the time of the Antonine Wall has been noted by Tipping $\&$ Tisdall (2005), who suggest that where this woodland persisted it would have been a managed resource by local people to provide wood for fuel and timber.

The assemblage from Building 2 (C042) is extremely limited, particularly in contrast to that from the rubbish pit outside this structure (see below). Only a very limited number of barley and spelt wheat grains were recovered from this building (see Table 6). Charcoal fragments analysed from this structure show that oak, hazel and cf plum/rowan timbers were utilised, probably for fuel.

The Building 3 assemblage (C094) is much more diverse and far richer than that of either of the previous two buildings. A large quantity of both charred cereal grain and wild taxa were recovered. Over 1,500 grains were identified from the fill, with barley grains dominating the assemblage and smaller amounts of spelt wheat and oat also present (see Table 6). On the whole, the assemblage is similar to that from Building 1, but on a much larger scale. The large number of grains from this single context suggests that Building 3 may have been used as, or was near to, a granary on the site before it was burnt down. Together with the grain, rachis fragments of barley and possible spelt wheat were present in rare amounts. This small quantity of chaff-related material suggests the crop was relatively clean and had thus been processed elsewhere. However, seeds of arable weeds such as ribwort plantain, buttercups, docks (Rumex sp) and pale persicaria (Persicaria lapithifolia) within the assemblage indicate that the remains of some ruderals were able to survive the cleaning process. A large quantity of grass caryopses also occur within the assemblage, the large majority of which have been identified as small-grained grasses (see Table 6). The presence of such large numbers of grasses may relate to one or a combination of: grasses growing as arable weeds and being collected with the crop during harvesting; grasses being used as bedding or flooring; grasses present in turf being burnt as fuel and/or used as a construction material. Of particular note is the presence of heath grass in the assemblage, which does not commonly grow in arable fields today, but is thought to have been a common agricultural weed in the past, until it was removed from the field ecosystem as a result of the change from the ard to the mould-board plough during the medieval period (Hillman 1981). Charcoal analysis from this structure indicates that oak and hazel were the primary fuel woods used (see Table 8).

The assemblage from C106, the fill of pit $\mathrm{C} 105$, within a potential structure was similar to that of Building 3, containing a large quantity of cereal grain. However, the assemblage here is dominated by oat rather than barley, and wheat is absent altogether (see Table 6). The presence of a large quantity of 
oat grain, compared to the other plant assemblages from the site, could suggest that the grain stored in an associated building was being used for a different purpose. One possibility is that the oat may have been used for feeding livestock such as horses, thus indicating the potential presence of a cavalry unit housed at Doune. However, Huntley \& Stallibrass (1995) considered this regarding other Roman forts and could not find an obvious correlation between sites with oat grain and those which housed cavalry units.

Only a small number of wild taxa were recovered from $\mathrm{C} 106$, which include sorrel, wild radish (Raphanus raphinistrum) and hemp-nettle (Galeopsis $\mathrm{sp})$. These again are largely indicative of arable weeds, with wild radish in particular notorious as a troublesome weed (Clapham et al 1962). Charcoal fragments identified from this structure show that alder is the dominant wood type used, with oak and hazel present together with possible birch and plum/rowan wood.

Two contexts from individual pits located between Buildings 2 and 3 were sampled. The fill of Pit 090 (C091), that closest to Building 3, was found to contain only a single grain of possible spelt wheat (Triticum cf spelta) together with a rare quantity of oak and possible hazel charcoal fragments, and as such offers little insight into the function of the pit. The fill of Pit 047 (C046) just outside of Building 2 , however, contains a much larger assemblage of cereals, dominated by barley (see Table 7). It is thought this pit may have been a post hole relating to Building 2 that had the post removed during the destruction of this structure. The assemblage from the pit fill contains a larger number of grains than was recovered from the building itself. Together with hulled barley, the assemblage also contains a small number of oat grains and wild taxa associated with arable land such as ribwort plantain, buttercups, grasses and sheep's sorrel. The pit is also noted to contain fragments of burnt wattle and daub relating to the destruction of the building and thus the grain may relate to storage of cereals within Building 2 , the majority of which was not exposed during excavation. Charcoal fragments from Pit C047 were found to consist only of oak, which may relate to fuel; oak was also recovered from Building 2 C042.

Samples were analysed from 12 contexts (C005, 009, 012, 015, 017, 018, 021, 028, 035, 044, 045 and 046) relating to Building 5. Charred cereal grain within the building appears to be concentrated within the rectangular pits $\mathrm{C} 014$ (C015 and 018) and $\mathrm{C} 029$ (C028, 044, 045 and 046), a buried soil layer $(\mathrm{C} 005)$ and the upper fill of construction trench 034 (C035), situated between the two pits. There is a general scatter of grain across the other contexts sampled, with grains present in low quantities, together with occasional wild taxa of largely arable weed species including fat-hen (Chenopodium sp cf C album), mustards (Sinapis sp) and buttercups. The grain assemblages from pits C014 and 029, occupation layer $\mathrm{C} 005$ and construction trench C034 are dominated by a mixture of spelt wheat and hulled barley. The Pit C014 assemblage is seen to be dominated by spelt wheat, with over 120 grains present in one context (015), while that from Pit C029 is dominated by hulled barley, with two-row barley in particular appearing to be the favoured variety used (see Table 7). The assemblages from construction trench $\mathrm{C} 035$ and buried soil $\mathrm{C} 005$ are a mixture of both spelt wheat and hulled barley, with spelt wheat being the most abundant species present.

The high numbers of spelt wheat found within Building 5 contrasts with that of the assemblages from the DPS99 excavation, where hulled barley was generally the dominant taxon (with the exception of Pit C105 (C106) where large numbers of oat grains were recovered). The large quantity of spelt wheat recovered from Building 5 may reflect a shift in cereal production between the lives of the buildings or differential storage of cereals within Building 5 . Along with spelt wheat and hulled barley, smaller quantities of bread/club wheat, emmer wheat and oat are also present in the assemblage from Building 5. A post hole from this building (C017) contained only two cereal grains: one of naked barley (Hordeum vulgare var nudum) and one of emmer wheat. The presence of naked barley, which is more prevalent on prehistoric sites, may represent either reworked material or a remnant crop.

The two pits (C014 and 029) together with high concentrations of grain also contain rich wild taxa assemblages (see Table 7). The assemblages contain a number of arable weed species, such as buttercups, ribwort plantain, corn marigold, sheep's sorrel and fumitories (Fumaria sp), which are likely to have been transported with the grain during 
harvesting. Together with the arable component of the assemblages, a significant quantity of taxa from wet/damp habitats is present. These are particularly well illustrated by the diverse sedge assemblage recovered, with species present including possible downy-fruited sedge (Carex sp cf $C$ filiformis), large yellow-sedge (Carex sp cf $C$ flava) and slender sedge (Carex sp cf $C$ elongata), which grows in wet places such as reed beds (Clapham et al 1962). Other damp ground taxa present include cinquefoil (Potentilla sp cf $P$ erecta), great wood-rush (Luzula sp cf L sylvatica) and common spike-rush (Eleocharis sp cf E palustris). Also of note is the significant number of grasses recovered within the pits. This mixture of charred grain, arable weeds and damp/wet ground taxa is likely to reflect the mixing of the occupation and destruction layers following the destruction of the building, which is thought to have been burnt down. The sedges and other wet plant taxa are likely to represent the use of turf/peat in the construction of Building 5, such as for the wattle (shown by the presence of daub) and/or for the roofing of the building. The concentration of sedges and grasses within the pits could also relate to some form of lining, but the separation of materials from the occupation and destruction layers is extremely difficult (eg Gustafsson 2000) and thus it is difficult to say with any certainty to which they may relate.

One context (C021) was sampled from a construction trench fill within the partially exposed Building 6 (see Table 6). The assemblage from Building 6 contains only a very limited number of charred plant remains consisting of a single hulled barley grain and a single mustard fruit. As such, the assemblage does not provide any information on the function or construction of the building. 